\title{
Essential Coaching Skills for Affective Development
}

\author{
Candice Dowd Barnes ${ }^{1 *}$, Morgan B. Bullard ${ }^{1} \&$ Patricia Kohler-Evans ${ }^{1}$ \\ ${ }^{1}$ University of Central Arkansas, Conway, Arkansas, United States \\ *Candice Dowd Barnes, E-mail: cbarnes@uca.edu
}

Received: August 30, 2017 Accepted: September 8, 2017 Online Published: September 29, 2017

doi:10.22158/jecs.v1n2p176 URL: http://dx.doi.org/10.22158/jecs.v1n2p176

\begin{abstract}
The goal of coaching for school improvement generally focuses on academic achievement. Coaching is often centered on raising test scores and ensuring that all students achieve academic standards. The effectiveness of coaching can also be found in its usefulness for developing affective skills in both teachers as well as students. Essential coaching skills of listening, paraphrasing, presuming positive intent, asking powerful questions, and providing reflective feedback can be paired with a focus on relationships and relatedness between coach and teacher, teacher candidate or student to positively impact the climate and culture of a classroom. With that in mind, coaching for affective development addresses the development of rapport, respect, and responsiveness to student needs. Utilizing coaching skills to develop students in both affective and academic domains strengthens the power of the coaching relationship.
\end{abstract}

\section{Keywords}

coaching, social and emotional development, coaching skills

\section{Introduction}

Effective coaching focused at the classroom level, with an emphasis on the implementation of research-based instructional strategies for all students, has great potential for generating student gains. Coaching is unlike many other instructional roles as it is set with the goal of creating meaningful change. Coaching for affective development draws upon feelings, cognition, and behavior, the main subcomponents of emotion, as well as one's attitudes, values, and beliefs. Therefore, coaching for affective development addresses how personality traits, characteristics, dispositions, emotions, thoughts, physiology, and value system affect the way a person authentically interacts with others. Coaching for affective development encompasses how we connect to other's emotions, our ability to regulate our emotions and interactions, and how we address the elements of relatedness.

In this article, coaching is discussed from multiple perspectives. The process of coaching occurs between university faculty and teacher candidates, school administrators and teachers, teachers and their colleagues (teacher to teacher), teacher and student, teacher candidate and student, as well as with 
numerous other sets of relationships. When discussing the process of coaching, the authors refer to the person doing the coaching as the mentor coach, teacher coach, or simply coach, regardless of any additional professional roles that person also fills (school leader, peer, supervisor, or faculty member). The recipient of coaching is generally referred to as the person being coached although this individual is sometimes referred to as teacher, student, or teacher candidate, depending on the role they play.

It is the responsibility of the coach to guide the mentee or protégé to conclusions, solutions, and other pertinent questions that will support their implementation practices. This is, of course only one of the many duties the coach may perform. There are also times in which the coach may act as a counselor, and as we suggest later, a thinking partner for their mentee. Therefore, there has to be substantive and sometimes, structured professional development and training provided to the coach. For example, the professional development provided to the coach might include: strategies for managing conflict, how to asking open-ended, thought provoking questions, methods to help structure the session time to ensure the coaching is effective. The training might also include content that explains the difference between coaching and mentoring.

Coaching for affective development is established and rooted in a relationship-centered approach. How can we see the connection between relationship and effective coaching? What are the essential skills necessary for a coaching relationship to be effective? How do these critical coaching skills impact not only student outcomes, but also classroom and culture? By focusing on and developing these essential coaching skills, an instructional and relationship-centered coach, whether he/she is a colleague, supervisor, university professor, or other professional can have a profound impact on classroom instruction and overall classroom climate.

Coaching has the potential to be most effective when the specific skills of committed listening, paraphrasing, presuming positive intent, asking powerful questions, and providing reflective feedback are paired with genuine relationship between the coach and the person being coached. Along with these essential coaching skills, accentuation is put on relatedness and relationships between the coach and the student or teacher. According to Parker, Barnes and Kohler-Evans (2016), there are five key elements to relatedness: relationship, routines, respect, responsiveness, and rapport. Each element has great potential for creating an impact within the climate and culture of a classroom, however, coaching for affective development is most closely aligned to developing rapport, respect, and being responsive to the needs of the person being coached. Coaches must create a classroom context where both the teacher or student and the coach feel emotionally safe and open to connection. With the five key elements of relatedness in mind, the essential coaching skills of listening, paraphrasing, presuming positive intent, asking powerful questions, and providing reflective feedback are critical when coaching for affective development. 


\section{Growing a Thinking Partnership}

Developing rapport, respect, and responding to the needs of the teacher or student can be a delicate balance of patience and understanding. A coach should know the teacher/student, both personally and professionally. This allows for the coach to gain greater insight or awareness into who the teacher or student is as persons and not just the way they are presented in one setting. A coach should work to understand what the person's values and beliefs are about learning, their students, and their classroom, as well as how their personality traits and characteristics influence what they do. If a teacher or student shares stories of triumph, graceful failures, or their personal experiences; this provides insight into their emotional functioning and who they are as both teacher or student and person.

The coach, in these instances, creates a space to engage the teacher or student in learning outcomes, meaningful strategies, and deep thinking to grow the partnership to achieve the highest expectations. Therefore, rapport between the coach and the coached can be easily lost if not cultivated consistently. Respect is gained when trust is established. Responsiveness is enhanced by a sense of care and consideration between the two. Like Rome, rapport and respect were not built in a day. It takes time, and in some cases, great effort to create a relationship-centered context to effectively coach for affective development. As compared by Dave Stachowiak (2017), founder of Coaching for Leaders, in relationships you should be an air traffic controller, not a pilot. A pilot is an expert in their field. They are the person who flies the plane. We should modestly be the air traffic controllers providing guidance and direction as the relationships and conversations go. So, how do we do this? What kind of skills could be utilized in order to create an open and exploratory atmosphere?

\section{Committed Listening}

As the old adage, people don't care what you know until they know you care suggests, unless one knows they are cared about (listened to), it does not matter what the message is. Listening is critical in coaching as it works to meet the basic wants of others: to be valued, to be understood, and to be cared about. One of the first individuals to put the spotlight on the great importance of listening was Steven Covey (1989) with his fifth habit that urges people to first seek to understand others before jumping to be understood themselves (p. 53). Covey gives prominence to the concept that sharing a strategy or a new behavioral program, which are often aspects of coaching, is best received when the one to whom the strategy or program is being offered is being genuinely heard. A simple failure to be heard can result in frustration, dissatisfaction, and even resentment for the person at both the giving and the receiving end of the listening.

Committed listening is more than the traditional definition that first pops to mind when seeing the word listening. It is more than just hearing a person when they speak. Covey further explains that most people only listen with the intent to reply when they should be listening with the intent to understand (p. 239). So then we ask, what is committed listening? A committed listener exhibits several behaviors: concentrating on what the speaker is saying; setting aside judgement; finding a solution, or personal stories during the 
discourse; allowing the speaker to complete his/her thoughts before speaking; listening for the whole message (verbal and nonverbal); recognizing that words do not necessarily mean the same to everyone; honoring another's views even when different from one's own; and refraining from providing advice. Figure 1 displays the critical elements of committed listening.

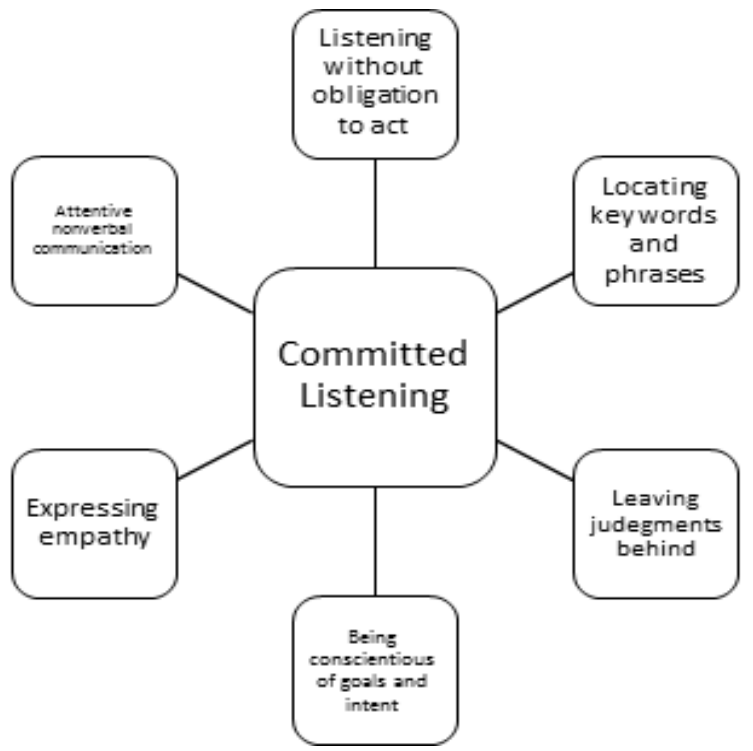

Figure 1. Elements of Critical Listening

According to Kee, Anderson, Deering, Harris and Shunster (2010), listening is foundational. Committed listening may sound daunting, but it is simply being fully present with another human being. Learning more about their personal and professional triumphs and struggles signals to the person that the coach cares and is genuinely interested in their welfare, and not just improving the quality of their teaching. In coaching for affective development, a committed listener can make all the difference.

\section{Paraphrasing}

Paraphrasing is the second essential skill a coach must have on their tool belt. Paraphrasing is generally defined as a way to express another person or another speaker's meaning using different words. Sometimes paraphrasing brings greater clarity to the speaker's perspectives. Paraphrasing is taking the important aspects of what the student, speaker, or teacher has said and rephrasing them in a reflective, thoughtful manner. Paraphrasing goes hand in hand with committed listening. It is taking what we just heard the speaker say and attempting to identify the true intention of the words spoken. Returning to Stephen Covey's fifth habit, seek first to understand, then to be understood, an essential element of understanding means checking with the speaker through use of a powerful paraphrase, one that, in essence says, "This is what I heard; is this what you meant to say?".

Principles of quality paraphrasing include being fully attentive by setting aside competing distractors or barriers, listening with the intent to understand, capturing the essence of the message, reflecting on the 
essence of voice tone and gestures, and paraphrasing before asking questions (Costa \& Garmston, 2002; Lipton \& Wellman, 2001). Quality paraphrasing has many of the same benefits as committed listening. Paraphrasing allows us to clarify content and let the speaker know that you understand what they are saying. It sends powerful messages to the speaker that you are listening, you care, and you are attempting to understand.

\section{Presuming Positive Intent}

Presuming positive intent refers to the coach's beliefs and thoughts about what the speaker is saying. This skill revolves around presuppositions we make every day. We gather these thoughts from language, language cues, past and present actions of others, etc. Judgements are made all the time, and our language reflects that. Langshur and Klemp (2016) suggest that judgement is a force that helps us make sense of the world, yet our judgments, left unexamined, can leave us focused on what is wrong in the world, in ourselves, as well as others. As a coach, we must also avoid making assumptions based on our impressions and perceptions of their personality characteristics and our prior experiences with other people who might share similar characteristics as the person with whom we are coaching.

With coaching, presuming positive intent versus lack of positive presumptions is vital. Coaches who presume positive intent influence an increase in improved outcomes for the teacher or student being coached. Conscientious coaches who presume positive intent are aware of their own presuppositions and choose words with care. One's language has the ability to shape thoughts, feelings, and experiences, and a skilled coach uses language to fully to ensure positive intent by becoming aware of his/her habitual ways of speaking. This level of awareness allows the coach to look for the best outcome for teachers or students by ensuring confidence in them with improved communication.

In an interview with Fortune Magazine (2008), CEO of PepsiCo Indra Nooyi gave an insightful look into the meaning of presuming positive intent. She proposed that if you assume positive intent with another person, you will be amazed at the potential outcomes. When communicating major points with others, removing negative intent allows you be open and precise in your responses. You don't get defensive or emotional as you are allowing yourself to attempt to understand the basic core of what another person is saying.

Three key behaviors have been identified by the authors of Powerful Coaching (2013), an accredited coach training program: a) the listener presumes the speaker has positive intentions in all actions and behaviors, b) the listener presumes the speaker has previously thought, said or done what the speaker is asking about, and the listener's language reflects this, and c) the listener uses positive presuppositions in his/her own language to indicate genuine belief in the thinking and actions of another. Through these behaviors, we are able to show as a coach that we believe in the positive intent of the speaker. Although sometimes difficult to do, presuming positive intent has the potential to make a sizeable difference in the effectiveness of a coaching relationship. 
Let's apply a scenario where intent is presumed by the teacher about the coach:

Emily meets her coach for the first time. She immediately sees him as an older male educator who has been in the field many years compared to herself as a young female teacher. She automatically assumes that he will be rigid in his teaching approach and therefore uninterested in many of the programs and activities she prides herself on in the classroom. Emily believes that he will be able to connect and relate to the majority of her rambunctious male students in a way that she feels she is unable. She admits she has hopes that her coach will also be able to assist her in managing the "less than ideal" behavior. Emily quickly learns that, while he is an older male educator that she immediately stuck into a certain mold, he actually enjoys seeing the activities taking place in her classroom that aren't just lecturing. Emily learns that he has struggled as well with classroom management and misbehavior in the past. She learns that his upbringing is quite antithetical to many of her male students despite Emily's assumption that his experiences would be similar. He shares how rapport was a real issue for him with his male students. Many did not take him "seriously" as a male authority figure. Yet, in the face of this issue, he is still able to offer narratives full of ups and downs, celebrations and hardships that may help Emily with classroom management and organization. Emily's perception of her coach are changing and developing. The coach is no longer constrained by the negative presumptions or initial perceptions made by Emily. Thus, the coach now has an opportunity to work more effectively and intentionally with Emily.

\section{Asking Powerful Questions}

We have all had that moment when a friend, loved one, or even colleague has asked us a question that left us stunned and silent for a moment, the question that made us take a step into ourselves and ponder. These packed, yet sometimes simple questions sometimes leave us with a totally different perspective or even result in paradigm shift. Kee et al. (2010) accentuated that powerful questions are part of our everyday vocabulary. They are questions that lead to exploration, discovery, authentication, and a commitment to action.

Powerful questions grab the receiver's attention, but how do we differentiate between a powerful question and a not powerful question? According to Bearwald (2011), coaches should ask specific types of questions: those that target essential issues and behavior, those that are precise and lead to greater clarity, questions that generate specific, relevant information, those that explore values, and those that connect past, present and future. As most of us have heard at one point or another, open-ended questions are crucial in a helping relationship. Stephen Barkley (2005) discusses the importance of asking open-ended questions when working with teachers or teacher candidates, indicating that open-ended questions are best because the answer that comes from a person controls the direction, not the actual question itself (p. 56). Open-ended questions are normally characterized by how they facilitate the conversation in a way that allows the receiver of the question to answer in as much detail as they deem necessary in their own way. In order to use open-ended questions effectively, the coach should pay special attention to learning how to hone their own personal skill. These are not "yes" or "no" questions. 
These are not questions that are looking to be responded to with a fact or simple response. Here are a few basic examples of open-ended questions:

- What does mean to you?

- $\quad$ Tell me about that.

- In what way has this inspired you to make a change?

- How did this come about?

- What do those feelings stem from?

When open-ended questions are combined with the aforementioned skills, specifically committed listening and presuming positive intent, the questions asked by the coach become thought-provoking, intellectually engaging, and call upon the receiver to have self-reflection and insight into their own thoughts and behaviors.

\section{Providing Reflective Feedback}

Providing feedback may sound simple on the surface, yet like other coaching skills, it is difficult to do in such a way that feedback is received as non-judgmental and evaluation-free. Traditionally, feedback has usually been given as judgement, a personal observation, inference, some type of data, or questions (Costa \& Garmston, 2002). That is not what we are looking for when applying coaching skills to affective development. Remember that we are a member of a thinking partnership, not just a coach giving out good advice based on what has been observed. As defined by Kee et al. (2010), requirements for reflective feedback are: be specific, be generous, ask permission before providing feedback, remember the goal is self- directed learning, and avoid negative feedback. Reflective feedback from a coach shows others that we are genuinely listening, working to understand what is being said, and being attentive to that. Branch and Paranjape (2002) asserts that reflection allows one to integrate concepts and skills, along with content knowledge and social and emotional development. This affords one to assimilate their thinking into new frames and use their new learning to improve.

As previously stated, the essential coaching skills outlined are part of the critical relationship/partnership building between a coach and a student. Jim Knight's (2007) partnership principles may apply with feedback more so than with any other of the coaching skills. Equality implies that both coach and individual being coached are co-equals, with thoughts and beliefs held to be equally valuable. Choice means that the teacher is integral in the communication process and adds to the process voluntarily and implicitly.

Voice suggests that both partners have opportunities to express their points of view. Dialogue means that coaches listen more than they tell. Reflection suggests that the person being coached is able to make sense of whatever the coach is proposing; true partners do not dictate what is to be believed. Finally, praxis implies that teachers may reconstruct and use content in whatever way they consider most useful. In order to give reflective feedback, we must utilize our skills of committed listening, paraphrasing, presuming positive intent, and asking powerful questions. When a coach combines all these skills 
together, feedback that is honest, effective, positive, and specific should come graciously to us with thought.

\section{Relatedness and Partnership}

When coaches are developing a trusting, credible, thinking partnership with others, a level of emotional and supportive safety is created that leaves space for a coach to effectively utilize the essential coaching skills for affective development. Five essentials to developing rapport and trust, and responding to the needs of others can increase the effectiveness of our work.

1) Know the person you are working with. Get to know them better, make them feel comfortable, lead in with open-ended questions. Use the skills you have learned to facilitate a relationship.

2) Encourage the teacher or student to share what they value and believe about learning and their work.

3) Learn how personality characteristics influence motivation.

4) Honor the teacher or student's position. Respect them as members in the thinking partnership, not just as a receiver of good advice.

5) Directly discuss the areas the teacher or student desires to enhance. Help them identify and reflect upon their goals and successes for coaching.

Without a relationship, there can be no effective coaching. The teacher must be able to positively relate and connect to the coach, otherwise the coaching will fall short of expectations. Effective coaching for affective development requires that coaches must be able to facilitate the building of a bridge between themselves and the teacher or student in hopes that they are able to fully explore the opportunity of development and change. Building rapport to cultivate trust and openness is easier when built from genuine positive thinking versus a defensive point of view. As the coach, we want the teacher or student to be motivated to think, learn, and trust.

\section{Dress Rehearsal}

Let's continue to follow Emily's story from the earlier example and reflect on how the five essentials for rapport and trust combine with the skills discussed throughout this article. At the end are questions to engage one's thinking about how their coaching practices affect the teacher's affective development and promotes change.

Emily struggles to collect and decide upon a solution to her problems of behavior and organization in her classroom. While the two issues are separate, she feels that they are also potentially connected. As she likes to keep her classroom full of fun activities and different ways of portraying information, Emily shares what areas she strongly enjoys such as art, painting, and writing. Many students thrive in the opportunity to express themselves in her class and connect to Emily in that way. She is very happy and honored by students' willingness to explore similar areas as her, but, at the same time, there are multiple students she feels refuse to climb aboard the activities and meld with her. This is upsetting for Emily, and 
she presumes that this also creates a boundary between her and the students when generating rapport and creating an efficient, potent relationship.

Mr. Allen is assigned to Emily as a coach after she shares these thoughts. He makes a point to make a structured cooperative meeting time everyday to meet and discuss the happenings of her classroom. On top of the exchanging discourse about the classrooms, Mr. Allen expresses interest in getting to know about Emily as a person. What does she think of her students? What are her goals? What has led her to this coaching time? What does she value in her work? By doing this Mr. Allen creates an atmosphere for not only him to get to know Emily as a person, but also for her to explore herself. Mr. Allen reinforces her place and knowledge in the classroom, and Emily is free from the feelings of judgment or criticism. This gives Emily a chance to look at the worth in her ideas and her strengths. It gives her the opportunity to delve into how to build upon her own personal successes and triumphs while also hearing some of Mr. Allen's as well. Together, they are able to create a bridge between their knowledge and experiences to grow a thinking partnership.

After working together for a few weeks, Emily becomes comfortable with Mr. Allen in a way that she feels prepared to share an idea for how she might be able to facilitate the creation of a connection between her and her uncooperative student who has not shown interest in her activities and relation before. During their organized meeting time, Emily brings up a potential plan for a new project that may do just that. Due to Mr. Allen's commitment to growing a thinking partnership with Emily by using committed listening, paraphrasing, presuming positive intent, asking powerful questions, and providing reflective feedback over the past few weeks, he is confident that Emily has an idea that focuses on her values and interests she has mentioned numerous times, but also creatively incorporates the other students who have found themselves uninterested thus far. By jointly exploring and coaching, Emily and Mr. Allen are able to work together to organize a way for more of the students to become involved and potentially build a connection between the more difficult-to-reach students and Emily.

\section{Questions for Reflection}

In order to develop your skills as a coach, please consider these questions for reflection.

- How did Mr. Allen and Emily foster a sense a rapport, respect, and responsiveness in the scenario?

- Which essential coaching skills are strengths for you? Which ones do you see more as weaknesses?

- In what ways do you honor the speaker through your committed listening? How did Mr. Allen and Emily effective implement committed listening?

- In what ways do you post powerful questions to challenge the speaker to get to the root of what they are meaning?

- How do you infuse care, respect, and honesty into your reflective feedback?

- Which essential coaching skills are strengths for you? Which ones do you see more as weaknesses? 


\section{References}

Barkley, S. G. (2005). Quality teaching in a culture of coaching. Lanham, MD: Rowman Littlefield.

Bearwald, R. R. (2011). It's about the questions. Educational Leadership, 69(2), 74-77.

Branch, W. T., \& Paranjape, A. (2002). Feedback and reflection. Academic Medicine, 77(12, Part 1), 1185-1188. https://doi.org/10.1097/00001888-200212000-00005

Burley-Allen, M. (1995). Listening: The forgotten skill (2nd ed.). New York: John Wiley \& Sons, Inc.

Coaching for Results Global. (2013). Powerful Coaching: Level II.

Costa, A. L., \& Garmston, R. J. (2002). Cognitive coaching: A foundation for renaissance schools (2nd ed.). Norwood, MA: Christopher-Gordon.

Covey, S. R. (1989). The seven habits of highly effective people: Powerful lessons in personal change. New York, NY: Simon \& Schuster.

Kee, K., Anderson, K., Dearing, V., Harris, E., \& Shuster, F. (2010). Results coaching: The new essential for school leaders. Thousand Oaks, CA: Corwin Press.

Knight, J. (2007). Instructional coaching: A partnership approach to improving instruction. Thousand Oaks, CA: Corwin Press.

Knight, J. (2011). What good coaches do. Educational Leadership, 69(2), 18-22.

Langshur, E., \& Klemp, N. (2016). Start here: A groundbreaking, science-based program for emotional fitness. New York, NY: North Star Way.

Nooyi, I. (2008). The best advice I ever got. Fortune. Retrieved February 27, 2017, from http://www.archive.fortune.com/galleries/2008/fortune/0804/gallery.bestadvice.fortune/7.html

Oxford English Dictionary. (2017). The definitive record of the English Language.

Parker, T., Barnes, C. D., \& Kohler-Evans, P. (2016). Success favors well-prepared teachers. Rowman \& Littlefield Publishers.

Stachowiak, D. (2017). 11 Ways to Facilitate Great Conversations. Coaching for Leaders. Retrieve August 29, 2017, from https://www.linkedin.com/pulse/11-ways-facilitate-great-conversationsdave-stachowiak 